\title{
Scaling of offspring number and mass to plant and animal size: model and meta-analysis
}

\author{
A. Jan Hendriks $\cdot$ Christian Mulder
}

Received: 15 December 2006/Accepted: 12 December 2007/Published online: 15 January 2008

(C) The Author(s) 2008

\begin{abstract}
The scaling of reproductive parameters to body size is important for understanding ecological and evolutionary patterns. Here, we derived allometric relationships for the number and mass of seeds, eggs and neonates from an existing model on population production. In a separate metaanalysis, we collected 79 empirical regressions on offspring mass and number covering different taxa and various habitats. The literature review served as a validation of the model, whereas, vice versa, consistency of isolated regressions with each other and related ecological quantities was checked with the model. The total offspring mass delivered in a reproductive event scaled to adult size with slopes in the range of about 3/4 to 1 . Exponents for individual seed, egg and neonate mass varied around $1 / 2$ for most heterotherms and between $3 / 4$ and 1 for most homeotherms. The scaling of the progeny number released in a sowing, clutch or litter was opposite to that of their size. The linear regressions fitted into a triangular envelope where maximum offspring mass is limited by the size of the adult. Minimum seed and egg size scaled with weight exponents of approximately 0 up to $1 / 4$. These patterns can be explained by the influence of parents on the fate of their offspring, covering the continuum of $r$-strategists (pelagic-aquatic, arial, most invertebrates,
\end{abstract}

Communicated by Bernhard Schmid.

\section{A. J. Hendriks ( $\square)$}

Department of Environmental Science, Radboud University Nijmegen, P.O. Box 9010, 6500 GL Nijmegen, The Netherlands e-mail: a.j.hendriks@science.ru.nl

\section{Mulder}

Laboratory for Ecological Risk Assessment, National Institute for Public Health and the Environment, P.O. Box 1,

3720 BA Bilthoven, The Netherlands

e-mail: christian.mulder@rivm.nl heterotherms) and $K$-strategists (littoral-terrestrial, some invertebrates, homeotherms).

Keywords Macroecology $\cdot$ Reproduction · Allometric scaling $\cdot$ Body size $\cdot$ Fecundity

\section{Introduction}

Scaling of processes and patterns to body size has fascinated biologists for centuries (e.g., Peters 1983; Damuth 2007). Plant and animal characteristics have been correlated to organisms' body mass $(m)$ by simple scaling relationships of the form $a \cdot m^{\mathrm{b}}$ or, if $\log$ transformed, $\log (a)+b \log (m)$. Properties include various reproductive parameters, such as the mass and number of the offspring, important for understanding life history strategies of species. The scaling of reproduction reflects several important trade-offs, e.g., investment of energy in somatic versus gonadic growth, in continuous or intermittent release and in many small or a few large offspring.

Studies have derived empirical regressions for offspring mass and number within one taxon (see review by Peters 1983). In addition, several partly contradictive physical, biochemical and ecological constraints related to parental energy investment, have been hypothesized to be responsible for the observed patterns (May 1978; Gordon 1989; Reiss 1989; Charnov and Downhower 1995; Hendry et al. 2001; Charnov 2001, 2002; Aarssen 2005). Although the trade-offs in reproductive investment reflect universal dilemmas that every species has to face, most work so far has covered either several progeny characteristics within a single species group or a single offspring parameter within at most two taxa (Moles et al. 2005a; Grubb et al. 2005). 
In the present paper, we will focus on the relationship of offspring mass and number to adult weight for miscellaneous groups of species. The aim is to obtain a set of straightforward equations that are coherent with allometric theory and underpinned by empirical regressions available in literature. To this end, we will first derive body-size functions for the mass and number of offspring delivered in a reproductive event which comply with allometric macroecology (e.g., West et al. 1997; Hendriks 1999). Next, we will compare the acquired relationships to independent empirical regressions collected in a meta-analysis. Separating model development and testing allows for a comparison of theoretical and empirical evidence, reducing weaknesses of both. In this approach, model predictions of, e.g., offspring mass, are underpinned by independent measurements. Likewise, isolated empirical regressions for this reproductive parameter are checked for consistency with body-size dependence of related ecological factors, such as population production or survival.

In our analysis, we will seek a balance between model transparency and accuracy, needed for underpinning assumed mechanisms and identifying exceptions. The equations are not intended to cover detailed or speculative differences, observed in empirical regressions for sufficient taxa. In our interpretation, we will follow the classical distinction between $r$-strategists and $K$-strategists (MacArthur and Wilson 1967; Pianka 1970) as well as more recent applications thereof (Winemiller and Rose 1992; McCann and Shuter 1997; Cox and Moore 2005). However, it should be emphasized that the traditional classification of many small offspring versus few large offspring as used in the present paper is no more than a convenient way to structure the discussion.

\section{Materials and methods}

\section{Regression collection and treatment}

Allometric regressions derived from data before 1983 were collected from an extensive review (Peters 1983). Papers published afterwards were obtained by screening books and by an electronic literature search in Web of Science in 2006. All body-size correlations acquired for the metaanalysis were checked in the original papers. Collection and treatment of data by the authors was assumed to be adequate. Where multiple types of regressions were reported, we took the least-squares equations, to increase compatibility with the other studies. If regression characteristics were not given or suspected to be wrong, we derived them from the original data or digitized graphs.

To allow for comparison, all values were converted to fresh biomass, using dry-wet weight fractions. A database containing dry matter fractions of 110 species, collected by the present authors for various purposes, yielded averages (with 95\% confidence intervals) of 20\% (18-22\%) for herbs, $22 \%$ (19-25\%) for invertebrates, $25 \%$ (18-32\%) for coldblooded vertebrates and 30\% (21-39\%) for warm-blooded vertebrates. In addition, the literature reports means of $53 \%$ for wood, 15-21\% for fruit, $87 \%$ for seeds, 23 for insects, $19 \%$ for marine invertebrates, $25 \%$ for fish and $29 \%$ for birds and mammals (Peters 1983; Suzuki 1999). Although the samples may be somewhat biased towards particular taxa, average levels do not deviate substantially. In the present analysis, we therefore used dry-wet weight fractions of $20 \%$ for fruits, forbs, herbs and invertebrates, of $25 \%$ for coldblooded vertebrates, of $30 \%$ for warm-blooded vertebrates, of $40 \%$ for shrubs and trees (wood and leaves together) and of $80 \%$ for seeds. Differences between species around these values have, on average, a negligible influence on the intercept of the regressions. Even more apparent, conversion does not affect the slope of the allometric relationships. Seeds mass was multiplied by $80 / 20 \%=4$ to arrive at the fresh weight of sprouts with a water content that is comparable to that of eggs and neonates. Since total plant weight is not used as the independent variable for vegetation regressions, we took the closest alternatives, being the aboveground or stem mass. In one study on insects, animal size was expressed on a length basis instead of a weight basis (Berrigan 1991). For these regressions, length (m) was converted to weight $(\mathrm{kg})$ as mass $=1 / 15^{2} \pi \times 10^{3}$ length $^{3}$, assuming that the total size equals 1.5 times the elythra length and twice the abdomen length.

Rate constants for reproduction of plants were reported as annual standing reproductive mass delivered by all plants, including both reproducing and non-reproducing individuals. We assumed that the seed and fruit mass are renewed each year. For animals, total clutch mass reflected the total reproductive mass released in an event or present in ovaries, sometimes calculated in the original studies as a product of the total number of eggs (neonates) in a clutch (litter), the number of eggs per clutch (neonates per litter) and the egg (neonate) weight.

To allow for comparison between plants, invertebrates, cold-blooded vertebrates and warm-blooded vertebrates, we calculated the arithmetic average of all slopes $(b)$ reported for each taxonomic group. To correct for differences in the amount of information included in the regressions, we also computed an average weighted by the number of data. For instance, the weighted average of a regression with $b=0.5$ and $n=10$ and another with $b=0.3$ and $n=20$ was calculated to be $0.5 \times 10 / 30+0.3 \times 20 / 30=0.37$. As we are interested in both the absence and presence of links to organism mass, weak and insignificant correlations were included in the analysis as well. Where used, however, they will be explicitly mentioned in the text. 
Model development

The relationship of offspring mass and size to adult weight can also be derived theoretically from previous modeling efforts (Hendriks 2007). The starting point in this model is production because coefficients and slopes of allometric regressions for this parameter differ only slightly for various groups of species. The rate constant for population turnover (production $k_{\mathrm{p}}$ ), measured as the production/biomass ratio $(P / B)\left(\mathrm{kg} \mathrm{kg}^{-1} \mathrm{day}^{-1}\right)$ is related to adult mass $(m)$ as:

$k_{\mathrm{p}}=q_{\mathrm{T}} \cdot \gamma_{\mathrm{p}} \cdot m^{-\kappa}$.

The exponent $(\kappa)$ was close to $1 / 4$ for a wide range of cold-blooded species but tended to be somewhat higher for homeotherms (Peters 1983; Hendriks 1999, 2007). The coefficient $\left(\gamma_{p}\right)$ represents the intercept at the standard temperature of $20^{\circ} \mathrm{C}$ and has a universal value of $7.5 \times 10^{-4} \mathrm{~kg}^{\kappa} \mathrm{day}^{-1}$ for all species (Hendriks 2007). Following biochemical reaction kinetics, the intercept increases by a factor of $q_{\mathrm{T}}$ as a function of temperature (Gillooly et al. 2001). Production $k_{\mathrm{p}}$ by warm-blooded species with a body temperature of $37^{\circ}$ is $q_{\mathrm{T}}=3.5$ times higher than that of equally sized cold-blooded species at $20^{\circ} \mathrm{C}$ (Hendriks 2007).

Production $k_{\mathrm{p}}$ is allocated to somatic and gonadic growth. We will consider the rate constant for reproduction (reproduction $k_{\mathrm{pr}}$ ) to be a fraction $\left(p_{\mathrm{rp}}\right)$ of total production $k_{\mathrm{p}}$ according to:

$$
\begin{aligned}
k_{\mathrm{pr}} & =p_{\text {rp }} \cdot k_{\mathrm{p}} \\
& =p_{\mathrm{rp}} \cdot q_{\mathrm{T}} \cdot \gamma_{\mathrm{p}} \cdot m^{-\kappa} .
\end{aligned}
$$

In Spermatophyta, $7 \%$ of the total dry weight production is diverted to reproduction via seeds (Niklas and Enquist 2002). After correction to a dry-wet weight fraction of $20 \%$ as described in the methods section, the reproductive fraction $\left(p_{\mathrm{rp}}\right)$ equals $28 \%$ (Table 1$)$. In animals, $p_{\mathrm{rp}}$ varies between 0 for juveniles and 1 for adults without somatic growth. Filling in the slope and the intercepts, yields the reproduction rate constant as a function of $m$ (Fig. 1).

Usually seeds, eggs and neonates are not delivered continuously but released in discrete batches, i.e., sowings, clutches and litters. The total offspring mass $\left(m_{\mathrm{r}}\right)$ accumulated in a period between two successive reproductive events $\left(\tau_{\mathrm{r}}\right)$ equals:

$m_{\mathrm{r}}=p_{\mathrm{rp}} \cdot k_{\mathrm{p}} \cdot m \cdot \tau_{\mathrm{r}}$.

The inter-reproductive interval $\left(\tau_{\mathrm{r}}\right)$ might be related to the organisms' metabolism and to environmental conditions. Initially, we did not find empirical regressions that link $\tau_{\mathrm{r}}$ to organism size. However, many other biological time

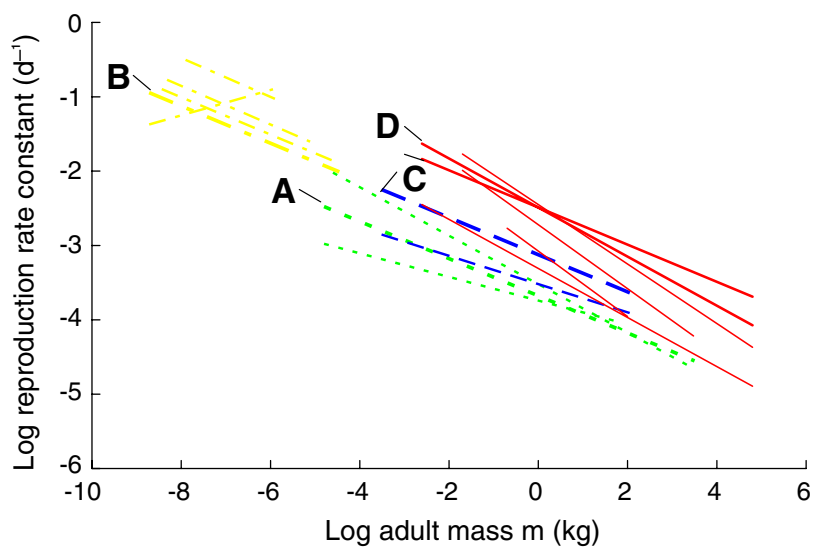

Fig. 1 Reproduction rate constants $\left(k_{\mathrm{pr}}\right)\left(\mathrm{kg} \mathrm{kg}^{-1} \mathrm{day}^{-1}\right)$ decrease with adult mass $(m)(\mathrm{kg})$ to the power of about 1/4-1/3. Model estimations (thick lines with letter) as well as empirical regressions (thin lines) for vascular plants $(A$, green dotted), invertebrates $(B$, yellow dashed-dotted), cold-blooded vertebrates $(C$, blue dashed) and warmblooded vertebrates $(D$, red solid $)$, as listed in Table $2 . \mathrm{d}^{-1}$ Day ${ }^{-1}$

\begin{tabular}{|c|c|c|c|}
\hline Symbol & Description & Unit & Value $^{\mathrm{a}}$, source \\
\hline$\gamma_{\mathrm{p}}$ & Scaling coefficients for production & $\mathrm{kg}^{\kappa}$ day $^{-1}$ & $7.5 \times 10^{-4}($ Hendriks 2007$)$ \\
\hline$k_{\mathrm{p}}, k_{\mathrm{pr}}$ & Rate constants for production and reproduction & day $^{-1}$ & Equation 1 \\
\hline$\kappa$ & Scaling exponent & - & $\mathrm{p}, \mathrm{c}, \mathrm{w} 1 / 4,{ }^{\mathrm{w}} 1 / 3$ (Hendriks 2007 ) \\
\hline$m$ & Adult mass & $\mathrm{kg}$ & Variable \\
\hline$m_{\mathrm{r}}$ & Total reproductive mass in a batch & $\mathrm{kg}$ & Equation 5 \\
\hline$m_{\mathrm{e}}$ & Seed, egg or neonate mass & $\mathrm{kg}$ & $\min \left(m_{\mathrm{e}}\right)=10^{-10},{ }^{\mathrm{i}} 10^{-10},{ }^{\mathrm{p}, \mathrm{acv}} 10^{-7},{ }^{\mathrm{tcv}} 10^{-3} \ldots \mathrm{m}_{\mathrm{r}} / 3$ \\
\hline$p_{\mathrm{rl}}$ & Fraction inter-reproductive period of average life time & - & 0.2 \\
\hline$p_{\text {rp }}$ & Fraction of production directed to reproduction & - & ${ }^{\mathrm{P}} 0.28$ (Niklas and Enquist 2002), ${ }^{\mathrm{i}, \mathrm{v}} 1$ \\
\hline$R_{0}$ & $\begin{array}{l}\text { Fecundity, number of offspring released } \\
\text { in a reproductive event }\end{array}$ & no. individual ${ }^{-1}$ & Equation 6 \\
\hline$q_{\mathrm{T}}$ & Temperature quotient & - & ${ }^{\mathrm{p}, \mathrm{c}} 1,{ }^{\mathrm{w}} 3.5$ (Hendriks 2007) \\
\hline$\tau_{\mathrm{r}}$ & Inter-reproductive period & day & Equation 4 \\
\hline
\end{tabular}

Table 1 Main factors used in the equations

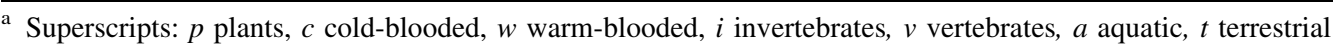


parameters, including gestation and weaning time of homeotherms, scale to $m$ with an exponent of $\kappa$ (Peters 1983; Hendriks 1999). For an average mammal, the age at birth, weaning off and average death is at about $2,3,50 \%$ of the total period from conception to death, respectively (Peters 1983). $\tau_{\mathrm{r}}$, covering at least gestation and weaning $(2+3 \%)$, thus equals at least $(2+3 \%) / 50 \%=10 \%$ of the average lifetime $\tau_{1}$, i.e., $\tau_{\mathrm{r}}=p_{\mathrm{rl}} \cdot \tau_{1}>10 \% \cdot \tau_{1}$. To allow for additional time to recover and mate we set the interreproductive period at a fraction $\left(p_{\mathrm{rl}}\right)=20 \%$ of the average lifetime $\tau_{1}$. This lemma is indirectly demonstrated by one long-term study on metabolism, reproductivity and average lifetime $\left(\tau_{1}\right)$ of earthworms (Mulder et al. 2007). In fact, although no evidence of a correlation between $\tau_{\mathrm{r}}$ and the offspring was found, $\tau_{1}$ and $m$ were strongly correlated. Following a more general theory, $\tau_{1}$ can indeed be defined here as the mean residence period in the population and can thus be replaced by $1 / k_{\mathrm{p}}$ (Odum 1983). In this way, $\tau_{\mathrm{r}}$ can now be assumed to equal:

$\tau_{\mathrm{r}}=p_{\mathrm{rl}} \cdot \tau_{1}=\frac{p_{\mathrm{rl}}}{k_{\mathrm{p}}}$.

Filling in the parameter values for mammals yields $\tau_{1}=0.3 /\left(3.5 \times 7.5 \times 10^{-4} \mathrm{~m}^{-1 / 4}\right)=114 \mathrm{~m}^{1 / 4}$. This is a factor of 2 larger than the value of $55 \mathrm{~m}^{0.23}\left(r^{2}=0.37\right.$, $n=41$ ) derived from a compilation of data on South American mammals that was published after our estimation (Pereira and Daily 2007). Obviously, this relationships needs to be confirmed for other species groups.

Substituting Eq. 4 into Eq. 3 yields the reproductive mass $\left(m_{\mathrm{r}}\right)$ accumulated between batches as a linear function of adult size ( $m$ ) as (Fig. 2):

$m_{\mathrm{r}}=p_{\mathrm{rp}} \cdot p_{\mathrm{rl}} \cdot m$.

The total reproductive mass derived from Eq. 5 can be divided into many small or a few large young. At one end of the interval, species called " $r$ "-strategists here,

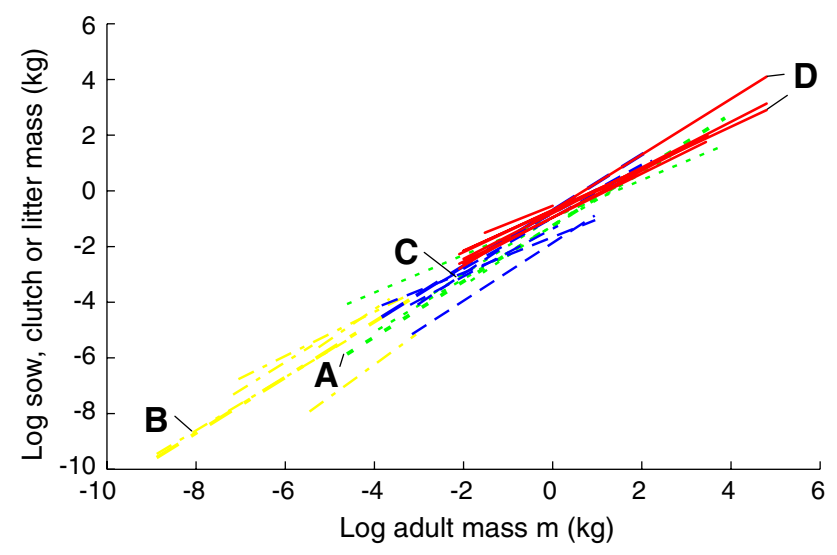

Fig. 2 Clutch or litter (reproductive) mass $\left(m_{\mathrm{r}}\right)(\mathrm{kg})$ increases with $m$ (kg) to the power of about 3/4 to 1 . Legend as in Fig. 1 . Regressions listed in Table 3 maximize the number of young per female $\left(R_{0}\right)$ up to a limit set by the absolute minimum size $\left[\min \left(m_{\mathrm{e}}\right)\right]$ of a seed, egg or neonate. The existence of such a threshold has been attributed to various restrictions but, to our knowledge, supporting quantitative evidence is still lacking. Since each individual starts off as a single cell, the average size of parental cells may serve as a first indication for the minimum egg or seed mass $\left(m_{\mathrm{e}}\right)$. The weight of a cell is reported to be in the range of $10^{-15}-10^{-11} \mathrm{~kg}$ for plants and animals (Raven 1998; West et al. 2001; Mulder et al. 2005). Lower taxa with multi-cellular organization, such as mycorrhizal conidia and fruit bodies of basidiomycetes, actually release offspring as single cells (Mulder et al. 2003). Higher species reproduce by multi-cellular sexual spores, seeds, eggs and neonates, with sizes at or above that range. With this variability in $\operatorname{mind}, \min \left(m_{\mathrm{e}}\right)$ was tentatively set at the minimum observed for the taxon covered (Table 1). At the other side of the range, " $\mathrm{K}$ "-type organisms invest all reproductive mass into a few young. In this strategy, seed, egg and neonate mass are maximized by dividing the total reproductive mass over a few offspring. Low values are noted for, e.g., birds with an average of 4.8 eggs per clutch and for mammals with means of 2.7-2.8 neonates per litter (Blueweiss et al. 1978; Ernest 2003). Apparently, the risk of premature death is typically spread over, on average, at least three young, so that the maximum mass of individual offspring $\left[\max \left(m_{\mathrm{e}}\right)\right]$ is calculated as $\max \left(m_{\mathrm{e}}\right)=m_{\mathrm{r}} / 3=p_{\mathrm{rp}} \cdot p_{\mathrm{rl}} \cdot m / 3$. With seed, egg and neonate mass ranging between $\min \left(m_{\mathrm{e}}\right)$ and $\max \left(m_{\mathrm{e}}\right)$, we can now derive $R_{0}$ as:

$$
\begin{aligned}
R_{0} & =\frac{m_{r}}{\min \left(m_{e}\right) \ldots \max \left(m_{e}\right)} \\
& =\frac{m_{r}}{\min \left(m_{e}\right) \ldots m_{r} / 3} \\
& =\frac{p_{r p} \cdot p_{r l}}{\min \left(m_{e}\right)} \cdot m . .3
\end{aligned}
$$

The number of seeds, eggs and neonates $\left(R_{0}\right)$ is thus expected to scale to $m$ with exponents in the range of $0-1$, for $K$-strategists and $r$-strategists, respectively. The corresponding intercepts are $p_{\mathrm{rp}} \cdot p_{\mathrm{rl}} / \min \left(m_{\mathrm{e}}\right)$ and 3 , respectively. Intermediate values indicate that both types of species are present in the sampled taxon. If strategies are uniformly distributed among species, one expects a mean slope of $1 / 2$, with the geometric average of $p_{\mathrm{rp}} \cdot p_{\mathrm{rl}} / \min \left(m_{\mathrm{e}}\right)$ and 3 as a coefficient. Vice versa, the mass of a seed, egg or neonate (i.e. $\left.m_{\mathrm{e}}\right)$ varies between $\min \left(m_{\mathrm{e}}\right) \propto m^{1}$ and $\max \left(m_{\mathrm{e}}\right) \propto m^{0}$, also with an average at $m^{1 / 2}$ (Figs. 3, 4).

Equations 4-6 apply to cases where $\tau_{\mathrm{r}}$ is related to the metabolism of the organisms. Alternatively, $\tau_{\mathrm{r}}$ may depend on cyclic processes in the environment. Since optimal conditions for offspring usually occur in specific seasons, synchronization of reproduction to annual cycles of 


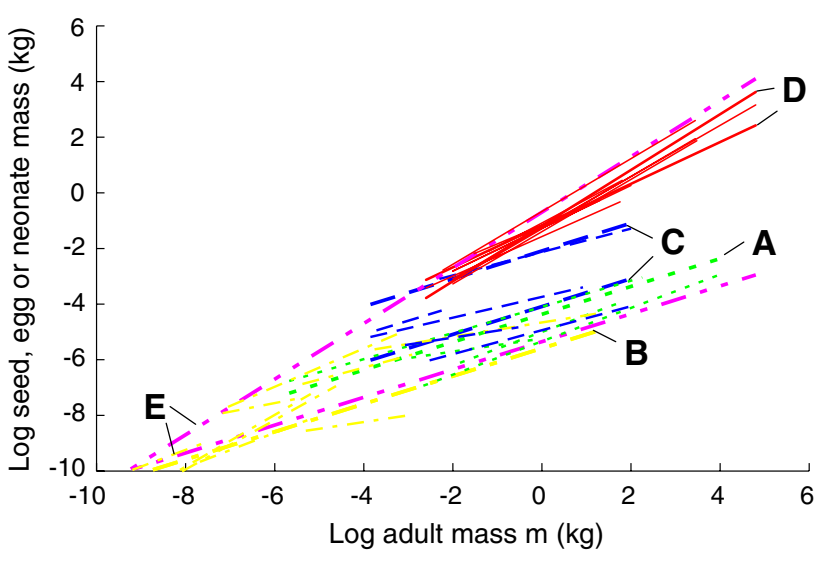

Fig. 3 Egg or neonate mass $\left(m_{\mathrm{e}}\right)(\mathrm{kg})$ increases with $m(\mathrm{~kg})$ to a power varying around $1 / 2$ for cold-blooded animals and in the range of 3/4-1 for warm-blooded animals. Legend as in Fig. 1; in addition, model estimations for organisms in general $(E$, dashed-dotted, $\left.m_{\mathrm{e}}=0.0000046 \mathrm{~m}^{1 / 2}, m_{\mathrm{e}}=0.2 \mathrm{~m}\right)$. Regressions listed in Table 3

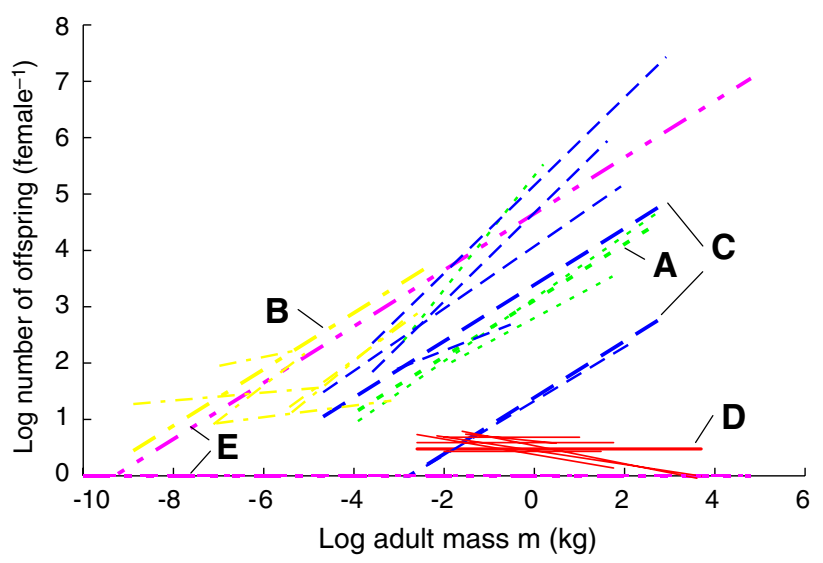

Fig. 4 Seed, egg or neonate number in ovaries, clutch or litter $\left(R_{0}\right)$ (young/individual) increases with $m(\mathrm{~kg})$ to a power varying around $1 / 2$ for cold-blooded animals and close to 0 for warm-blooded animals. Legend as in Fig. 1; in addition, model estimations for organisms in general $\left(E\right.$, dashed-dotted, $\left.R_{0}=45,000 \mathrm{~m}^{1 / 2}, R_{0}=1\right)$. Regressions as listed in Table 3

temperature, light or food availability by e.g., hibernation or fetal growth retardation, is most likely. With $\tau_{\mathrm{r}}=365$ days, Eq. 3 becomes:

$m_{\mathrm{r}}=p_{\mathrm{rp}} \cdot k_{\mathrm{p}} \cdot m \cdot 365=p_{\mathrm{rp}} \cdot q_{\mathrm{T}} \cdot \gamma_{\mathrm{p}} \cdot m^{1-\kappa} \cdot 365$

indicating that the mass released in a yearly sowing, clutch or litter $\left(m_{\mathrm{r}}\right)$ scales to $m$ with an exponent of $1-\kappa$. Organisms with an intrinsic $\tau_{\mathrm{r}}$ close to 1 year can exploit such synchronization most readily. Smaller species may somewhat postpone their reproduction, increasing the gonadic mass released. Larger species may do the opposite, decreasing the slope of the regression towards 3/4. Fitting Eq. 1 into 4 and writing $m$ explicitly gives: $m=\left(p_{\mathrm{rl}} \cdot \frac{1}{\tau_{\mathrm{r}} \cdot q_{\mathrm{T}} \cdot \gamma_{\mathrm{p}}}\right)^{(1 /-\kappa)}$

Using the typical values for the parameters (Table 1), cold-blooded and warm-blooded organisms with a $\tau_{\mathrm{r}}$ of 365 days are expected to have an $m$ of about 4 and $500 \mathrm{~kg}$, respectively. Organisms that are much smaller mature sufficiently fast to allow multiple generations within a year or growing season. Species which are substantially larger need more than 1 year to produce one egg or neonate.

\section{Results}

Reproduction rate constant

We will now compare the derived equations to the empirical regressions obtained in the meta-analysis. The few correlations available for gonadic growth show that reproduction $k_{\mathrm{pr}}$ indeed decrease significantly with increasing adult mass $(P<0.0001 \ldots<0.002$, Table 2$)$. Average slopes for plants and animals are in the range of -0.16 to -0.39 (Table 4). Slopes for warm-blooded species tend to be steeper than those for cold-blooded species. The empirical regressions for seed plants were derived from one study, with annual reproductive mass expressed as a function of foliage and stem mass because total weight correlations were not provided (Fig. 1; Niklas and Enquist 2003). The invertebrate regressions apply to short-term studies on different types of copepods. The outlier noted in field experiments with sac spawners was not confirmed by other correlations, including those for high food levels (Hirst and Bunker 2003, p 1,995). Low intercepts for fish and mammals apply to long-term observations, including intervals without gonadic growth (Charnov 2001; Charnov et al. 2001). High values were noted for reproductive growth in gestation periods (Payne and Wheeler 1968; Blueweiss et al. 1978). Reproduction within primates is slower, as earlier noted for production (Table 2, no. 34; Western and Ssemakula 1982; Hendriks 2007).

The differences between regressions for the reproduction $k_{\mathrm{pr}}\left(\mathrm{kg} \mathrm{kg}^{-1} \mathrm{day}^{-1}\right)$ follow the trends expected from the model, based on average turnover $k_{\mathrm{p}}$ (Eq. 2). That is to say, slopes $-\kappa$ for both reproduction and production tend to be close to $-1 / 4$ for heterotherms and at or below $-1 / 3$ for homeotherms (Table 4; White and Seymour 2004; Hendriks 2007). Intercepts for seed growth in plant populations, including all life stages, follow Eq. 2, independently confirming the value of $28 \%$ for the $p_{\text {rp. }}$. The reproduction rate regressions for animals are expressed on a female basis. With the exception of deviations noted for some regressions on copepods and primates, levels for true gonadic growth in 
Table $2 k_{\mathrm{pr}}\left(\mathrm{kg}\right.$ female $\left.\mathrm{kg}^{-1} \mathrm{day}^{-1}\right)$ as a function of $m(\mathrm{~kg})$ according to empirical regressions $\left(y=a m^{\mathrm{b}}\right)$ collected in the meta-analysis. For abbreviations, see Table 1

\begin{tabular}{llllrlll}
\hline No & Taxon & $a$ & \multicolumn{1}{l}{$l$} & \multicolumn{1}{l}{$r^{2}$} & $P$ & Source \\
\hline 1 & Spermatophyta & $1.8 \times 10^{-4}$ & -0.16 & 279 & 0.75 & $<0.0001$ & Niklas and Enquist (2003) \\
2 & Spermatophyta & $3.0 \times 10^{-4}$ & -0.33 & 418 & 0.75 & $<0.0001$ & Niklas and Enquist (2003) \\
11 & Copepoda & $9.7 \times 10^{-4}$ & -0.25 & 3081 & 0.06 & $<0.001$ & Hirst and Bunker (2003) \\
12 & Copepoda & $1.3 \times 10^{0}$ & 0.17 & 452 & 0.05 & $<0.001$ & Hirst and Bunker (2003) \\
13 & Copepoda & $2.7 \times 10^{-3}$ & -0.26 & 35 & 0.32 & 0.002 & Kiørboe and Sabatini (1995) \\
14 & Copepoda & $1.2 \times 10^{-3}$ & -0.26 & 10 & 0.72 & 0.002 & Kiørboe and Sabatini (1995) \\
21 & Osteichthyes & $3.0 \times 10^{-4}$ & -0.19 & 139 & 0.74 & $<0.0001$ & Charnov et al. (2001) \\
31 & Mammalia & $4.9 \times 10^{-4}$ & -0.33 & 192 & 0.89 & $<0.0001$ & Charnov (2001) \\
32 & Mammalia & $1.9 \times 10^{-3}$ & -0.43 & 92 & 0.65 & $<0.0001$ & Blueweiss et al. (1978) \\
33 & Mammalia & $3.6 \times 10^{-3}$ & -0.40 & 30 & 0.90 & $<0.0001$ & Payne and Wheeler (1968) \\
34 & Primates & $8.4 \times 10^{-4}$ & -0.44 & 15 & 0.93 & $<0.0001$ & Payne and Wheeler (1968) \\
\hline
\end{tabular}

heterotherms are within a factor of 3 of the model, based on a $\gamma_{\mathrm{p}}$ of $7.5 \times 10^{-4} \mathrm{~kg} \mathrm{~kg}^{-1} \mathrm{day}^{-1}$ previously derived for production (Fig. 1). In general, the variability of the intercepts for reproduction reflects differences in methods, conditions and species and is similar to the variability observed for, e.g., individual growth or consumption (Hendriks 2007). Keeping this variability in mind, we might approximate reproduction by $0.28 k_{\mathrm{p}}$ in plants and $1 k_{\mathrm{p}}$ in adult animals as predicted by Eq. 2 of the model.

Total offspring mass in a reproductive batch

With average production $k_{\mathrm{p}}$ as a predictor of reproduction, we can now compare measurements and estimations for the reproductive masses and numbers (Fig. 2). Regressions indicate that total seed, egg and neonate weight increase with parent size $(P<0.0001 \ldots<0.05$ in Table 3, Fig. 2). Most $95 \%$ confidence intervals for the average of the slopes encompass $3 / 4$ or 1 , but the whole animal size range can only be covered by an exponent of 1 (Table 4). The outcome for plants is dominated by a regression with a slope of 0.67 observed for fruit versus stem mass (1 in Table 3). Expressed on leaf mass, annual standing reproductive weight in plants scaled to 0.84 (Niklas and Enquist 2003). Comparing weighted averages, the mean slope for invertebrates 0.95 is significantly higher than the confidence interval calculated for plants and cold-blooded vertebrates (Table 4). The confidence intervals noted for exponents of birds and mammals cover 3/4 but not 1 . All intercepts for cold-blooded and warm-blooded species are close to each other with the exception of one low value noted for fish (Fig. 2, Table 3; Stolz 2005). This outlier, however, reflects year-round observations while other regressions apply to peak gonad mass. Similar intercept differences were noted for the reproduction $k_{\mathrm{pr}}$.
For the overall range, empirical slopes for heterotherms approach the value of 1 expected from Eq. 5 of the model. In addition, the intercepts for plants and animals are at the level expected from the coefficients $p_{\mathrm{rl}} \cdot p_{\mathrm{rp}}$ of Eq. 5 . Exponents collected for homeotherms and some largesized heterotherms tend towards 3/4, suggesting synchronization to annual cycles as explained by Eq. 7. The steep lines observed for invertebrates in comparison to the flatter slopes of cold-blooded vertebrates confirm the prediction that heterotherms of ca. $4 \mathrm{~kg}$ are likely to experience some kind of synchronization. In addition, exponents for mammals, including large species weighting up to $500 \mathrm{~kg}$, are close to 3/4. Exponents for birds are smaller and obviously their weight range does not include this value.

\section{Seed, egg and neonate mass}

Regressions show that seed and egg masses are significantly related to adult size for most heterothermic species groups $(P<0.05$, Table 3$)$. Exceptions are noted for some correlations that cover a small size range or a few data $(P \geq 0.07$; Table 3, nos. 2 and 3 and 20). The slope varies within a small interval around the mid-point value of $1 / 2$ (Fig. 3). Averages for invertebrates are higher than those for plants and cold-blooded vertebrates, mainly because regressions on egg-carrying copepods and wasps have slopes closer to 1 (Table 3, 12 and 16; Berrigan 1991; Kiørboe and Sabatini 1995). The egg and seed masses $\left(m_{\mathrm{e}}\right)$ for plants, invertebrates and (semi-)aquatic vertebrates of the same size are within 1 order of magnitude of each other (Fig. 3). Eggs of aquatic crustaceans tend to be smaller than those of terrestrial spiders and insects with equal body size (Table 3, nos. 12-14<14-18). Likewise, intercepts for cold-blooded vertebrates increase in the sequence of fish, water-bound salamanders, land-dwelling salamanders 


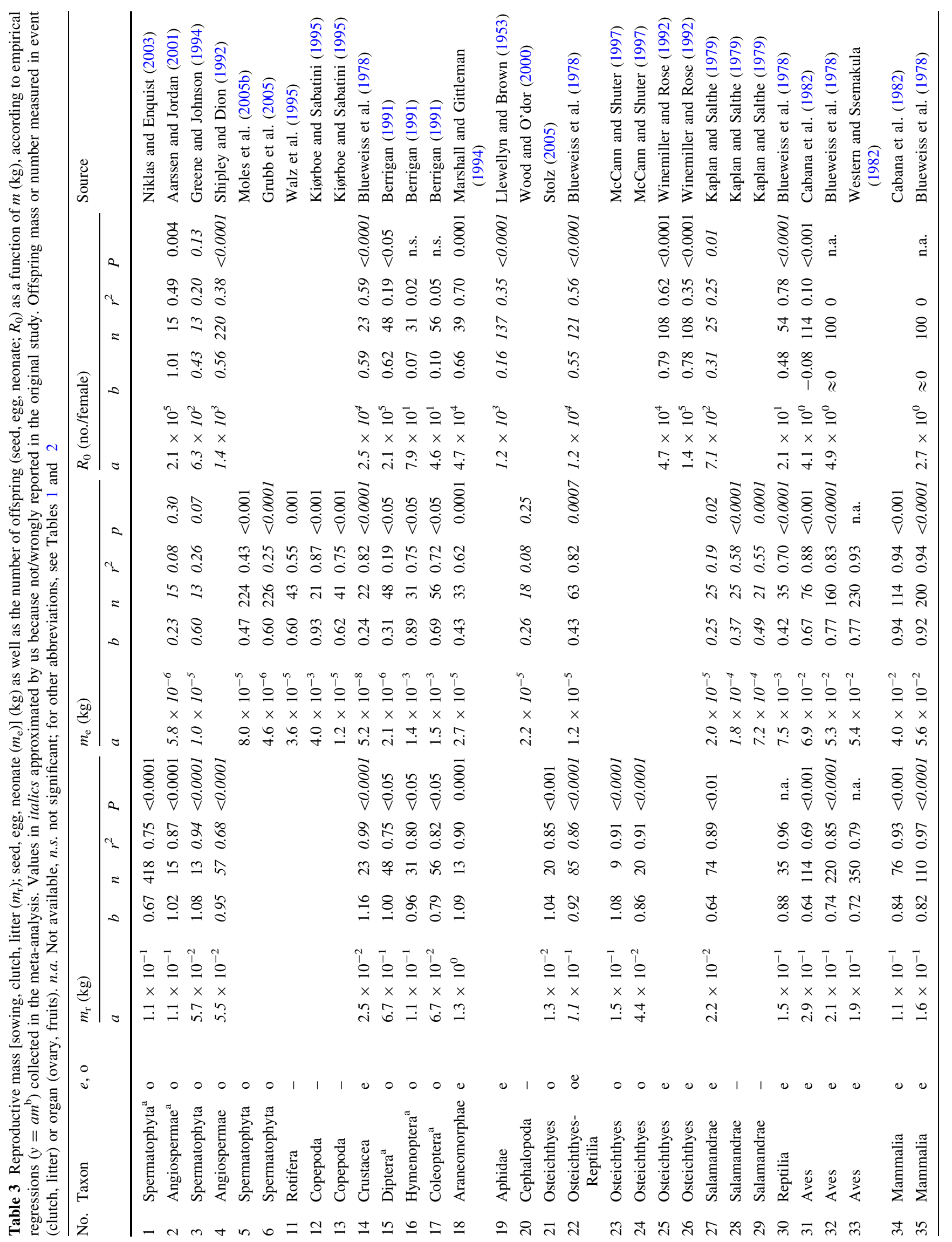




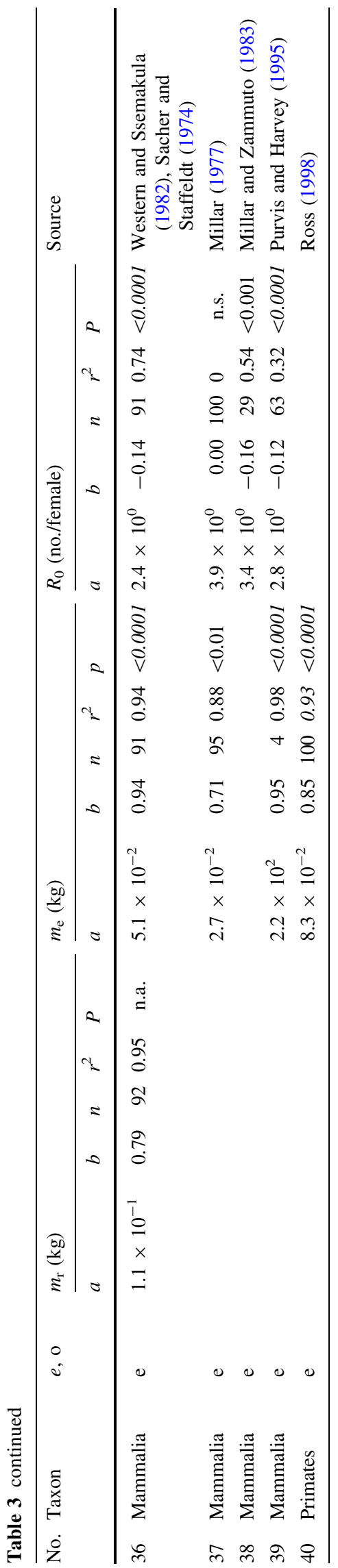

and reptiles (Table 3, $22<27<28 \leq 29<30$; Blueweiss et al. 1978; Kaplan and Salthe 1979). Warm-blooded animals distribute their reproductive effort over a small and size-invariant $R_{0}$, leading to exponents for egg and neonate mass $\left(m_{\mathrm{e}}\right)$ between 3/4 and 1 (Fig. 3).

The partitioning of the reproductive mass over seeds, eggs and neonate thus follows a combination of both strategies distinguished in the model. The empirical regressions collected are within the minimum and maximum boundaries set by Eq. 6 of the model (Fig. 3). The slopes for plants, most invertebrates and all cold-blooded vertebrates vary around $1 / 2$ indicating some intermediate value between $\min \left(m_{\mathrm{e}}\right)-m^{0}$ and $\max \left(m_{\mathrm{e}}\right)-m^{1}$. Egg-carrying copepods, wasps, birds and mammals largely consists of $K$-strategists, with egg and neonate mass $\left(m_{\mathrm{e}}\right)$ exponents near those noted for clutch and litter mass $\left(m_{\mathrm{r}}\right)$. Almost all regressions are above the intermediate intercept calculated by the model for an overall minimum offspring size $\min \left(m_{\mathrm{e}}\right)$ of $10^{-10} \mathrm{~kg}$ (Table 1). Using typical minimum values $\min \left(m_{\mathrm{e}}\right)$ of $10^{-7} \mathrm{~kg}$ for plants, fish and amphibians and of $10^{-3} \mathrm{~kg}$ for reptiles rather than the overall $10^{-10} \mathrm{~kg}$ gives a better fit of the model.

Seed, egg and neonate number

The number of seeds and eggs released by heterotherms scales to size with exponents largely between $1 / 2$ and 1 (Table 4, Fig. 4). The difference between intercepts reflects the fraction of the lifetime covered, being near $100 \%$ for herbs and a few percent of less for trees, reflecting lifetime and batch fecundity $\left(R_{0}\right)$, respectively (Table 3, 2 vs. 3-4; Shipley and Dion 1992; Greene and Johnson 1994; Aarssen and Jordan 2001). The amount of eggs delivered by crustaceans, flies, spiders and aphids is significantly correlated to adult size but those for wasps and beetles are size-independent (Table 3, nos. 14-15, 18-19 vs. 16-17; Llewellyn and Brown 1953; Blueweiss et al. 1978; Berrigan 1991; Marshall and Gittleman 1994). The low intercept for vertebrate heterotherms applies to reptiles (Table 3, 30; Blueweiss et al. 1978). The clutch and litter size of warmblooded species does not increase with adult size. In fact, four out of seven regressions have slightly negative slopes.

As expected, average slopes of regressions for $R_{0}$ are in the same range as those calculated for the ratio of total and individual offspring mass $\left(m_{\mathrm{r}} / m_{\mathrm{e}}\right)$ (Table 4$)$. The largest deviation between arithmetic means is noted for plants and equals $0.66-0.45=0.21$. However, this difference is due to one study in which sowing weight and number but not seed weight scale significantly to $m(b=1.01 \ldots 1.02$, $P<0.00001 \ldots 0.004$, vs. $b=0.23, \quad P=0.30)$. With parameters set at typical values, the model follows these trends (Table 1). 
Table 4 Allometric scaling of reproductive parameters as listed in Tables 2 and 3 plotted in Figs. 1-4. Measured arithmetic mean and dataweighted mean (in italics) for the regression exponent $b$ with 95\% confidence interval and model values. For abbreviations, see Tables 1 and 2

\begin{tabular}{|c|c|c|c|c|c|}
\hline Parameter & Reproduction rate & Batch mass & Offspring mass & Offspring number & \\
\hline $\begin{array}{l}\text { Symbol } \\
\text { Unit }\end{array}$ & $\begin{array}{l}p_{\mathrm{ap}} \cdot k_{\mathrm{p}} \\
\mathrm{d}^{-1}\end{array}$ & $\begin{array}{l}m_{\mathrm{r}} \\
\mathrm{kg}\end{array}$ & $\begin{array}{l}m_{\mathrm{e}} \\
\mathrm{kg}\end{array}$ & $\begin{array}{l}R_{0} \\
\text { Number of individuals }\end{array}$ & $m_{\mathrm{r}} / m_{\mathrm{e}}$ \\
\hline \multicolumn{6}{|l|}{ Empirical average } \\
\hline Plants & $-0.33,-0.16$ & $\begin{array}{l}0.93(0.65-1.22) \\
0.78(0.65-0.91)\end{array}$ & $\begin{array}{l}0.48(0.20-0.75) \\
0.53(0.45-0.60)\end{array}$ & $\begin{array}{l}0.66(-0.10 \text { to } 1.43) \\
0.58(0.38-0.78)\end{array}$ & $\begin{array}{l}0.45 \\
0.25\end{array}$ \\
\hline Invertebrates & $\begin{array}{l}-0.15(-0.49 \text { to } 0.19) \\
-0.20(-0.33 \text { to }-0.07)\end{array}$ & $\begin{array}{l}1.00(0.83-1.17) \\
0.95(0.87-1.03)\end{array}$ & $\begin{array}{l}0.55(0.35-0.75) \\
0.56(0.51-0.62)\end{array}$ & $\begin{array}{l}0.32(-0.04 \text { to } 0.68) \\
0.27(0.13-0.42)\end{array}$ & $\begin{array}{l}0.45 \\
0.39\end{array}$ \\
\hline Cold-blooded vertebrates & -0.19 & $\begin{array}{l}0.90(0.74-1.06) \\
0.85(0.78-0.91)\end{array}$ & $\begin{array}{l}0.39(0.28-0.50) \\
0.40(0.27-0.53)\end{array}$ & $\begin{array}{l}0.58(0.26-0.91) \\
0.67(0.54-0.81)\end{array}$ & $\begin{array}{l}0.51 \\
0.45\end{array}$ \\
\hline Birds & & $0.70(0.56-0.84)$ & $0.74(0.59-0.88)$ & $-0.04(-0.55$ to 0.47$)$ & -0.04 \\
\hline Mammals & $-0.39(-0.53$ to -0.25$)$ & $0.82(0.75-0.88)$ & $0.88(0.77-1.00)$ & $-0.08(-0.28$ to 0.11$)$ & -0.06 \\
\hline Model value & & & & & \\
\hline Cold-blooded & $-1 / 4$ & 1 & $1 / 2$ & $1 / 2$ & \\
\hline Warm-blooded & $-1 / 4$ to $-1 / 3$ & $(3 / 4)-1$ & $(3 / 4)-1$ & 0 & \\
\hline
\end{tabular}

\section{Discussion}

\section{Data variability}

The meta-analysis yielded regressions for various species groups. However, important phylogenetically lower taxa, such as bacteria, algae, fungi, mosses, ferns, Protozoa and annelids have not been included in allometric relationship on reproductive parameters. Budding or binary fission in unicellular organisms yields new cells that become independent at about $30-50 \%$ of the parent cell volume, respectively (Woldringh et al. 1993). Unicellular taxa thus maximize the mass rather than the number of their offspring. Fungi, mosses and ferns release spores that are at the lower end of the palynological range noted for seed plants (e.g., Nilsson 1983; Haig and Westoby 1991; Moore et al. 1991; Mulder and Janssen 1999). Their strategy is thus comparable to that of some seed plants, such as orchids. Additional study of the size-related reproduction of these cryptogams is required.

Plant offspring is characterized by seed and fruit mass with or without ancillary tissues, while adult mass refers to leaves and/or stems. Animal studies either cover the whole annual cycle or reproductive periods only. In addition, deviations from average values of other factors, such those for lengthweight conversion or life-stage may increase variability.

Slopes on the trade-off between reproduction and production

Despite uncertainties, clear patterns on the average trends emerge (Fig. 5). Reproduction $k_{\mathrm{pr}}\left(\mathrm{kg} \mathrm{kg}^{-1}\right.$ day $\left.^{-1}\right)$ decrease with size, as expected from the model. According to Eq. 2, reproduction is considered to be a fraction $\left(p_{\mathrm{rp}}\right)$ of the production $k_{\mathrm{p}}$, representing the $P / B$ of a population. Reproduction $k_{\mathrm{pr}}$ by homeotherms has steeper slopes and larger intercepts in comparison with heterotherms, as earlier noted for production $k_{\mathrm{p}}$ (Fig. 2, Table 2). It indicates that the trade-off between somatic and gonadic growth is rather invariant to size and metabolism. The fraction of the production directed to reproduction $\left(p_{\mathrm{rp}}\right)$ was found to be $28 \%$ for plants after conversion to seedling wet weight, indeed independent of the species weight (Niklas and Enquist 2002). The similarity between slopes for reproduction and overall population production indicates that such a relationship also exists for animals. However, the derivation of such a fraction is yet impeded by large variability among intercepts, by a lack of information on many heterothermic species and by the focus on adult animals instead of whole populations.

Slopes on the trade-off between offspring number and mass

The meta-analysis in the present paper shows that the mass released in a single reproductive event $\left(m_{\mathrm{r}}\right)(\mathrm{kg})$ is a constant fraction of the parents' weight for a remarkable variety of plant and animal species (Table 3, Fig. 2). Over the whole range of species studied, the slope is close to 1 but exponents for specific groups, such as homeotherms and possibly plants, are smaller. Ignoring differences in slopes and intercepts, about $20 \%$ of the adult mass is released in a sowing, clutch or litter (Eq. 5). This supports, though not necessarily implies, the existence of a size-independent $p_{\mathrm{rp}}$. 
In addition to the trade-off between somatic and gonadic growth, organisms may divert their reproductive mass over many small or a few large offspring (Fig. 5). In other words, the $R_{0}$ is inverse proportional to seed, egg or neonate mass $\left(m_{\mathrm{e}}\right)$. As elaborated in the Model development section, one may distinguish between species with $r$-tactics that maximize the number of offspring with increasing adult mass $\left(R_{0} \sim m^{1}, m_{\mathrm{e}} \sim m^{0}\right)$ and $K$-strategists that amplify seed, egg or neonate weight $\left(m_{\mathrm{e}} \sim m^{1}, R_{0} \sim m^{0}\right)$. Slopes of regressions on $R_{0}$ and $m_{\mathrm{e}}$ of the offspring generally vary around the intermediate value of $1 / 2$, expected if species with an $r$ - and $K$-strategy are equally distributed (Table 3). However, regressions on egg-carrying copepods, wasps, birds and mammals have exponents close to 1 for egg and neonate size $\left(m_{\mathrm{e}}\right)$ and near 0 for $R_{0}$ (Table 3 ). These species groups thus largely consist of $K$-strategists.

Graphically, seed, egg and neonate mass are confined to a triangular envelope that contains small species with small offspring and large species with small or large offspring (Figs. 3-5). Such a pattern has been previously recognized in original data on plants and fish. The triangle was found to be right-angled for fish, with a minimum egg size $\left[\min \left(m_{\mathrm{e}}\right)\right]$ of $10^{-7} \mathrm{~kg}$ independent of the $m$ (e.g., Duarte and Alearaz 1989). In plants, the envelope was reported to be obtuse-angled, where the 5\%-tile and the 95\%-tile of seed size scaled to total plant mass with exponents in the range of $0.21-0.32$ and $0.38-0.68$, respectively (Grubb et al. 2005; Moles et al. 2005b). The slopes for the lower boundary encompass the value of $1 / 4$, known for scaling of biological time variables (Peters 1983; Hendriks 1999). Although the period to adulthood has been suggested to limit egg and seed size, such a relationship may be more complex than a $1 / 4$ power scaling to size (see, e.g., Kiflawi 2006). In addition, some proof for the underlying mechanisms, including an explanation for its absence and

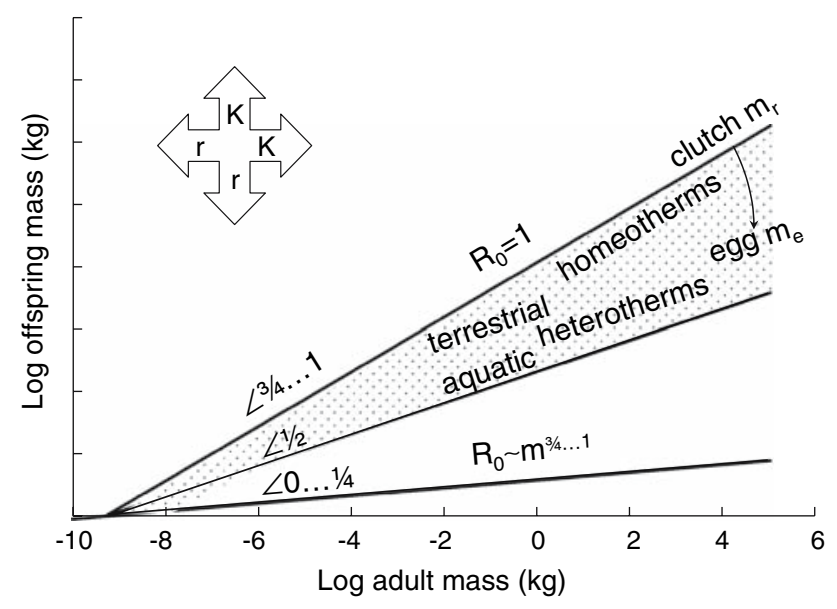

Fig. 5 Theoretical (lines) and empirical (dotted area) trends of seed, egg or neonate mass $\left(m_{\mathrm{r}}, m_{\mathrm{e}}\right)(\mathrm{kg})$ and number $\left(R_{0}\right)$ versus $m(\mathrm{~kg})$ for several species groups presence in different species, as well as taxon-specific slope values, is yet lacking.

Similar considerations apply to the upper boundary. The egg and neonate mass $\left(m_{\mathrm{e}}\right)$ in warm-blooded species is proportional to the weight of their parents. Each of the slopes is steeper than observed for clutch or litter mass $\left(m_{\mathrm{r}}\right)$. However, confidence intervals for the averages indicate that $3 / 4$ may be the appropriate exponent in addition to 1 , at least within small size ranges such as noted for birds. Slopes of 3/4 can be understood from inter-reproductive periods that synchronize to annual cycles rather than to adult mass (Eq. 7). Yet, the difference between cold-blooded $(\approx 1 / 2)$ and warmblooded [(3/4)-1] species indicate that metabolism-related mechanisms may be important too. Just as size of warmblooded adults appears to be constrained by heat exchange, neonate mass may be also be determined by thermodynamic principles. However, the exploration and underpinning of other values for the slopes is beyond the scope of the present paper. For now, we assume that the lower and upper end of the range scale to between 0 and 1 . Most species groups contain both an $r$ - and $K$-strategists yielding an average of slope of about $1 / 2$, whereas some animal taxa were shown to scale to 1 . Future refinement by thermodynamic principles may lead to a smaller range between, e.g., $1 / 4$ and 3/4, still yielding average slopes around 1/2.

Intercepts on the trade-off between aquatic and terrestrial habitats

Having described the possible values of the slopes, we will now take a look at the intercepts. The variability of the exponents excludes detection of subtle differences between coefficients. Yet, there is an evident increase in egg size from aquatic to terrestrial habitats, both among invertebrates and vertebrates. The difference has historically been attributed to oxygen limitations as its diffusion in air is 10,000 times faster than in water (Hendry et al. 2001). However, experiments within the same species do not confirm this explanation (Einum et al. 2002). We therefore suggest that an alternative, more universal, mechanism may be more important. A parent is more willing to invest in the size of a seed or egg when it can influence its fate. Organisms have little control of transport and development in large homogeneous compartments such as water and air. Consequently, clutches of aquatic animals consist of many small eggs (Fig. 4; Blueweiss et al. 1978; Kaplan and Salthe 1979; Berrigan 1991; Winemiller and Rose 1992; McCann and Shuter 1997; Wood and O'dor 2000). Even within fish, pelagic species reproduce by smaller and more eggs than demersal counterparts of equal size (Duarte and Alearaz 1989). The intercepts for the amphibians increase in the sequence of pond breeders that attach eggs to plants 
followed by stream and land breeders with nests (Table 3, $27<28<29$; Kaplan and Salthe 1979). Within the heterogeneous terrestrial environment, land animals can direct their offspring to sites that provide shelter or food to avoid wasting reproductive mass in unfavorable patches (Blueweiss et al. 1978; Berrigan 1991; Marshall and Gittleman 1994). The small seed size of terrestrial plants in comparison to egg masses in reptiles can be understood from the extra dispersal function of propagules in the former case.

Obviously, other factors that covary with the water-land gradient may be responsible for the observed patterns. For instance, the dry-wet weight fraction of adults increases from aquatic to terrestrial habitats and a similar trend might exist in their offspring too. However, this explanation, and the related interpretation, is unlikely to cover the orders of magnitude of the noted differences.

Integration of theoretical and empirical evidence

Integrating these trends, we can now derive common patterns within the triangular envelope of offspring and adult mass (Fig. 5). In general, $r$-strategists are found amongst small adults (Fig. 5, left-hand side) with many small offspring in aquatic environments (Fig. 5, lower end). Large adults (Fig. 5, right-hand side) with a few large young live in terrestrial habitats (Fig. 5, upper end). Obviously, these patterns cannot cover all reproductive and non-reproductive characteristics associated with $r-K$ gradients. For instance, ruderal plants typically reproduce as $r$-strategists, but more $K$-type species, especially in close canopies, may also regenerate via wind dispersal of small seeds (Grime et al. 1997; Grime 2001; Aarssen 2005). In addition, seed mass is known to be negatively correlated with the leaf size or the life span of 640 plant species (Díaz et al. 2004). Such results for plants strongly imply the existence of correlated traits in other taxa and demand further investigation.

Acknowledgements We thank Wilco Verberk, Bernhard Schmid and two anonymous reviewers for useful comments on an earlier version of the manuscript.

Open Access This article is distributed under the terms of the Creative Commons Attribution Noncommercial License which permits any noncommercial use, distribution, and reproduction in any medium, provided the original author(s) and source are credited.

\section{References}

Aarssen LW (2005) Why don't bigger plants have proportionately bigger seeds? Oikos 111:109-277

Aarssen LW, Jordan CY (2001) Between species patterns of covariation in plant size, seed size and fecundity in monocarpic herbs. Ecoscience 8:471-477
Berrigan D (1991) The allometry of egg size and number in insects. Oikos 60:13-32

Blueweiss L, Fox H, Kudzma V, Nakashima D, Peters R, Sams S (1978) Relationships between body size and some life history parameters. Oecologia 37:257-272

Cabana G, Frewin A, Peters RH, Randall L (1982) The effect of sexual size dimorphism on variations in reproductive effort of birds and mammals. Am Nat 120:17-25

Charnov EL (2001) Evolution of mammal life histories. Evol Ecol Res 3:521-535

Charnov EL (2002) Reproductive effort, offspring size and benefitcost ratios in the classification of life histories. Evol Ecol Res 4:749-758

Charnov EL, Downhower JF (1995) A trade-off invariant life history rule for optimal offspring size. Nature 376:418-419

Charnov EL, Turner TF, Winemiller KO (2001) Reproductive constraints and the evolution of life histories with indeterminate growth. Proc Natl Acad Sci USA 98:1134-1137

Cox CB, Moore PD (2005) Biogeography. An ecological and evolutionary approach. 7th edn. Blackwell, London

Damuth J (2007) A macroevolutionary explanation for energy equivalence in the scaling of body size and population density. Am Nat 169:621-631

Díaz S, Hodgson JG, Thomson K, Cabido M, Cornelissen JHC, Jalili A, Montserrat-Martí G, Grime JP, Zarrinkamar F, Asri Y, et al. (2004) The plant traits that drive ecosystems: evidence from three continents. J Veg Sci 15:295-304

Duarte CM, Alearaz M (1989) To produce many small or few large eggs: a size-independent reproductive tactic of fish. Oecologia 80:401-404

Einum S, Hendry AP, Fleming IA (2002) Egg-size evolution in aquatic environments: does oxygen availability constrain size? Proc R Soc Lond B 269:2325-2330

Ernest SKM (2003) Life history characteristics of placental nonvolant mammals. Ecology 84:3402. http://www.esapubs.org/archive/ ecol/E084/093/

Gillooly JF, Brown JH, West GB, Savage VM, Charnov EL (2001) Effects of size and temperature on metabolic rate. Science 293:2248-2251

Gordon IJ (1989) The interspecific allometry of reproduction: do larger species invest relatively less in their offspring? Funct Ecol 3:285-288

Greene DF, Johnson EA (1994) Estimating the mean annual seed production of trees. Ecology 75:642-647

Grime JP (2001) Plant strategies, vegetation processes, ecosystem properties. 2nd edn. Wiley, Chichester

Grime JP, Thompson K, Hunt R, Hodgson JG, Cornelissen JHC, Rorison IH, Hendry GAF, Ashenden TW, Askew AP, Band SR, et al. (1997) Integrated screening validates primary axes of specialization in plants. Oikos 79:259-281

Grubb PJ, Coomes DA, Metcalf DJ (2005) Comment on "A brief history of seed size". Science 310:783a

Haig D, Westoby M (1991) Seed size, pollination costs and angiosperm success. Evol Ecol 5:231-247

Hendriks AJ (1999) Allometric scaling of rate, age and density parameters in ecological models. Oikos 86:293-310

Hendriks AJ (2007) The power of size: a meta-analysis reveals consistency of allometric regressions for ecological modelling. Ecol Modell 205:196-208

Hendry AP, Day T, Cooper AB (2001) Optimal size and number of propagules: allowance for discrete stages and effects of maternal size on reproductive output and offspring fitness. Am Nat 157:387-407

Hirst AG, Bunker AJ (2003) Growth of marine planktonic copepods: global rates and patterns in relation to chlorophyll a, temperature, and body weight. Limnol Oceanogr 48:1988-2010 
Kaplan RH, Salthe SN (1979) The allometry of reproduction: an empirical view of salamanders. Am Nat 113:671-689

Kiflawi M (2006) On optimal propagule size and developmental time. Oikos 113:168-173

Kiørboe T, Sabatini M (1995) Scaling of fecundity, growth and development in marine planktonic copepods. Mar Ecol Progr Ser 120:285-298

Llewellyn M, Brown VK (1953) A general relationship between adult weight and the reproductive potential of aphids. J Anim Ecol 54:663-673

MacArthur RH, Wilson EO (1967) The theory of island biogeography. Princeton University Press, Princeton

Marshall SD, Gittleman JL (1994) Clutch size in spiders-is more better? Funct Ecol 8:118-124

May RM (1978) The dynamics and diversity of insect faunas. In: Mound LA, Waloff N (eds) Diversity of insect faunas. Blackwell, Oxford, pp 188-204

McCann K, Shuter B (1997) Bioenergetics of life history strategies and the comparative allometry of reproduction. Can J Fish Aquat Sci 54:1289-1298

Millar JS (1977) Adaptive features of mammalian reproduction. Evolution 31:370-386

Millar JS, Zammuto RM (1983) Life histories of mammals: an analysis of life tables. Ecology 64:631-636

Moles AT Ackerly DD, Webb CO, Tweddle JC, Dickie JB, Westoby M (2005a) A brief history of seed size. Science 307:576-580

Moles AT Ackerly DD, Webb CO, Tweddle JC, Dickie JB, Westoby M (2005b) Response to comment on "A brief history of seed size". Science 310:783

Moore PB, Webb JA, Collinson ME (1991) Pollen analysis. 2nd edn. Blackwell, London

Mulder C, Janssen CR (1999) Occurrence of pollen and spores in relation to present-day vegetation in a Dutch heathland area. $\mathrm{J}$ Veg Sci 10:87-100

Mulder C, Breure AM, Joosten JHJ (2003) Fungal functional diversity inferred along Ellenberg's abiotic gradients: palynological evidence from different soil microbiota. Grana 42:55-64

Mulder C, Van Wijnen HJ, Van Wezel AP (2005) Numerical abundance and biodiversity of below-ground taxocenes along a $\mathrm{pH}$ gradient across the Netherlands. J Biogeogr 32:1775-1790

Mulder C, Hendriks AJ, Baerselman R, Posthuma L (2007) Age structure and senescence in long-term cohorts of Eisenia andrei (Oligochaeta: Lumbricidae). J Gerontol A Biol Sci 62 (in press)

Niklas KJ, Enquist BJ (2002) On the vegetative biomass partitioning of seed plant leaves, stems and roots. Am Nat 159:482-497

Niklas KJ, Enquist BJ (2003) An allometric model for seed plant reproduction. Evol Ecol Res 5:79-88

Nilsson S (1983) Atlas of airborne fungal spores in Europe. Springer, Vienna

Odum HT (1983) Systems ecology. Wiley, New York
Payne PR, Wheeler EF (1968) Comparative nutrition in pregnancy and lactation. Proc Nutr Soc 27:129-137

Pereira HM, Daily GC (2007) Modeling biodiversity dynamics in countryside landscapes. Ecology 87:1877-1885

Peters RH (1983) The ecological implications of body size. Cambridge University Press, Cambridge

Pianka ER (1970) On $r$ - and $K$-selection. Am Nat 104:592-597

Purvis A, Harvey PH (1995) Mammal life-history evolution: a comparative test of Charnov's model. J Zool 237:259-283

Raven JA (1998) Small is beautiful: the picophytoplankton. Funct Ecol 12:503-513

Reiss MJ (1989) The allometry of growth and reproduction. Cambridge University Press, Cambridge

Ross C (1998) Primate life histories. Evol Anthropol 6:54-63

Sacher GA, Staffeldt EF (1974) Relation of gestation time to brain weight for placental mammals: implications for the theory of vertebrate growth. Am Nat 108:593-615

Shipley B, Dion J (1992) The allometry of seed production in herbaceous angiosperms. Am Nat 139:467-483

Stolz JA (2005) Allometric growth and sperm competition in fishes. J Fish Biol 67:470-480

Suzuki E (1999) Diversity in specific gravity and water content of wood among tropical rainforest trees. Ecol Res 14:211-224

Walz N, Sarma SSS, Benker U (1995) Egg size in relation to body size in rotifers: an indication of reproductive strategy? Hydrobiologia 313/314:165-170

West GB, Brown JH, Enquist BJ (1997) A general model for the origin of allometric scaling laws in biology. Science 276:122126

West GB, Brown JH, Enquist BJ (2001) A general model for ontogenetic growth. Nature 413:628-631

Western D, Ssemakula J (1982) Life-history patterns in birds and mammals and their evolutionary interpretation. Oecologia $54: 281-290$

White CR, Seymour RS (2004) Does basal metabolic rate contain a useful signal? Mammalian BMR allometry and correlations with a selection of physiological, ecological, and life-history variables. Physiol Biochem Zool 77:929-941

Winemiller KO, Rose KA (1992) Reproductive constraints and the evolution of life histories with indeterminate growth. Can J Fish Aquat Sci 49:2196-2218

Woldringh CL, Huls PG, Vischer NOE (1993) Volume growth of daughter and parent cells during the cell cycle of Saccharomyces cerevisiae as determined by image cytometry. J Bacteriol 175:3174-3181

Wood JB, O'dor RK (2000) Do larger cephalopods live longer? Effects of temperature and phylogeny on interspecific comparisons of age and size at maturity. Mar Biol 136:91-99 